\title{
Announcements and the Role of Policy Guidance
}

\author{
Carl E. Walsh
}

\begin{abstract}
By providing guidance about future economic developments, central banks can affect private sector expectations and decisions. This can improve welfare by reducing private sector forecast errors, but it can also magnify the impact of noise in central bank forecasts. I employ a model of heterogeneous information to compare outcomes under opaque and transparent monetary policies. While better central bank information is always welfare improving, more central bank information may not be. (JEL E52, E58)
\end{abstract}

Federal Reserve Bank of St. Louis Review, July/August 2008, 90(4), pp. 421-42.

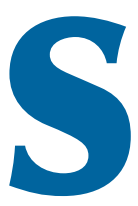

tandard models used for monetary policy analysis typically assume that households and firms and the central bank share a common information set and economic model, yet actual policy decisions are taken in an environment in which heterogeneous information is the norm and many alternative models coexist. The resulting heterogeneity in views can play an important role in affecting both policy choices and the monetary transmission process. Transparency in the conduct of policy can help to reduce heterogeneous information. Inflation-targeting central banks, for example, make significant attempts to reduce uncertainty about policy objectives, such as through the release of detailed inflation and output projections, to ensure the public shares central bank information about future economy developments. By being transparent about its objectives and its outlook for the economy, central banks help provide the public with guidance about the future.

But providing guidance carries risks. As Poole (2005, p. 6) has expressed it, "[F]or me the issue is whether under normal and routine circumstances forward guidance will convey information or whether it will create additional uncertainty."

Because any forecast released by the central bank is subject to error, being more transparent may simply lead the private sector to react to what was, in retrospect, noise in the forecast. The possibility that the private sector may overreact to central bank announcements does capture a concern expressed by some policymakers. For example, in discussing the release of Federal Open Market Committee (FOMC) minutes, Janet Yellen expressed the view that "Financial markets could misinterpret and overreact to the minutes" (Yellen, 2005, p. 1).

In this paper, I explore the role of economic transparency-specifically, transparency about the central bank's assessment of future economic conditions-in altering the effectiveness of monetary policy. I do so in a framework in which central bank projections may convey useful information but may also introduce inefficient fluctuations into the economy.

A focus on economic transparency seems appropriate for understanding the issues facing many central banks. The recent concerns about

Carl E. Walsh is a professor of economics at the University of California, Santa Cruz, and a visiting scholar at the Federal Reserve Bank of San Francisco.

(C) 2008, The Federal Reserve Bank of St. Louis. The views expressed in this article are those of the author(s) and do not necessarily reflect the views of the Federal Reserve System, the Board of Governors, or the regional Federal Reserve Banks. Articles may be reprinted, reproduced, published, distributed, displayed, and transmitted in their entirety if copyright notice, author name(s), and full citation are included. Abstracts, synopses, and other derivative works may be made only with prior written permission of the Federal Reserve Bank of St. Louis. 
the implications of the subprime mortgage market reflect, in part, private sector uncertainty about the Fed's view of the economic outlook and the way the outlook for inflation and real economic activity may be affected by financial market conditions. Throughout 2007, for example, many financial market participants appeared to hold more pessimistic views than the Federal Reserve about future economic developments; ${ }^{1}$ and in recent months, market participants have often expected significant interest rate cuts, while some members of the FOMC have emphasized concerns about the outlook for inflation, suggesting they saw less need for rate reductions. News reports speculating on possible interest rate cuts by the Fed or the European Central Bank focused very little on uncertainty about central bank preferences but a great deal on the uncertainty about the outlook for the economy. These reports reveal heterogeneity among private forecasters and uncertainty about the Fed's (or the European Central Bank's) outlook for the economy. And public statements by central bankers were designed to communicate their views on future economic developments. Jean-Claude Trichet's statement that the markets "have gone progressively back to normal" (Atkins, Mackenzie, and Davies, 2007, p. 1) and Ben Bernanke's (2007) comment that housing remains a "significant drag" on the economy, both exemplify how central bankers signal their assessment of economic conditions, and this assessment is one factor that influences the (heterogeneous) outlooks among members of the private sector.

The uncertainty in financial markets in recent months illustrates clearly the significant differences that can arise between the central bank and private market participants. This is a classic example of heterogenous information about the economy. Much of the debate has been focused on the question of future interest rate cuts, but the underlying issues appear to be related to differing views among private forecasters and between private

\footnotetext{
1 "Even as Wall Street analysts ratchet up their worries about a recession, Fed officials are far from convinced that a true downtown is likely" (Andrews, 2007). A more vivid example of disagreement was provided by CNBC commentator Jim Cramer, whose blast that the Fed is clueless about "how bad it is out there" was reportedly seen by more than a million viewers on YouTube.
}

forecasters and the Fed over the likely impact of financial market disturbances on the real economy and the likelihood of a future recession.

The next section discusses the two goals of transparency Bill Poole (2005) has stressedaccountability and policy effectiveness. The third section develops a model of asymmetric and heterogeneous economic information that can be used to model the implications of transparency. Two policy regimes are considered. In the first, the public observes the policy instrument of the central bank but the central bank provides no further information to the public. In the second, the central bank provides information on its outlook for future economic developments. The welfare implications of these regimes are discussed in the fourth section. Within each regime, better quality central bank information is always welfare improving (the pro-transparency aspect of Morris and Shin, 2002, emphasized by Svensson, 2006). However, across regimes, more central bank information has ambiguous effects.

\section{THE GOALS OF TRANSPARENCY}

Transparency requires asymmetric information, but the nature of this asymmetry can take many forms. In fact, Geraats (2002) has classified five types of transparency-political, procedural, economic, policy, and operational. Briefly, these correspond to central bank transparency about objectives, the internal decisionmaking process, forecasts and models, policy actions, and instrument setting and control errors. Each of these dimensions of transparency is important and has been studied extensively (see Geraats, 2002, for a survey).

In recent years, central banks have become more transparent along all these dimensions, and levels of transparency that would have been viewed as exceptional 20 years ago are today accepted as best practice among modern central banks. ${ }^{2}$ The trend toward independent central

\footnotetext{
2 See Eijffinger and Geraats (2006) and Dincer and Eichengreen (2007) for indices of central bank transparency. Cukierman (2006) discusses some of the factors that might place limits on how transparent central banks should (or can) be.
} 
banks with explicit mandates assigned to them and the widespread adoption of inflation targeting has contributed greatly to political transparency. The Bank of England is among the most procedurally transparent central banks, publishing minutes and individual votes of its Monetary Policy Committee discussions. Central banks, such as the Federal Reserve, that were formerly reluctant to communicate policy actions directly now do so clearly, timely, and directly. The most transparent central banks, such as the Reserve Bank of New Zealand and the Bank of Norway, publish their projections for the policy interest rate. The use of a short-term interest rate as the policy instrument has greatly enhanced operational transparency. But although most central banks today are transparent about their policy stance and operational procedures-something hard to avoid when the policy instrument is a short-term market interest rate-there is much greater variation in the extent to which central banks are transparent about their decisionmaking process, their internal forecasts, and their policy objectives.

But what is the point of being transparent? As noted earlier, Poole (2006) has articulated two goals of transparency: to meet the Fed's "responsibility to be politically accountable" and "to make monetary policy more effective.” The next two subsections discuss each of these goals.

\section{Transparency and Accountability}

The role transparency plays in supporting accountability can differ depending on whether the ultimate objectives of monetary policy are observable or unobservable. Consider first the case in which the objectives of monetary policy are, ex post, clearly measurable and observable. For concreteness, assume inflation is the only objective of the central bank and there is agreement on the appropriate measure of inflation that the central bank should control. In this environment, it is in principle straightforward to ensure accountability. Observing the ex post rate of inflation would seem to provide a simple means for judging the performance of the central bank. However, even under the conditions specified (a single measurable objective), the ex post realiza- tion of inflation is not a sufficient performance measure. The reason is that inflation is not directly controllable-even under an optimal policy (where the central bank is doing exactly what it should be doing), the realized inflation rate can differ from the desired value. This difference may be small, but as long as there is any random variation that is beyond the ability of the central bank to eliminate, public accountability based solely on inflation outcomes will punish some good central bankers and reward some lucky ones.

Transparency can help promote accountability by allowing the public to base its evaluation of the central bank not just on observed inflation but on the information that was available to the central bank when it had to make its policy decision. Having access to internal bank forecasts, for example, allows outsiders to evaluate the decisions made by the central bank. This can mitigate some of the problems associated with evaluations based solely on realized inflation. Having access to the information on which decisions were based helps remove the influence of random uncontrollable events that affect inflation and therefore supports a better system of accountability. ${ }^{3}$

In general, however, policy objectives are not directly observable, and they may even be inherently unmeasurable. Certainly, recent theoretical models, which have emphasized the use of the welfare of the representative agent as the appropriate objective of policy, have defined optimal policy in terms of unmeasurable objectives. It is not clear that we could reach agreement on the correct way to measure welfare, as that depends on the specific model we believe characterizes the economy, even if we could agree on how to define welfare. It certainly is not observable.

Transparency can be especially critical when objectives are unobserved. Assessing, or holding accountable, an economic agent when objectives are unobservable is not a situation unique to monetary policy and central banks. Education is perhaps the most prominent field in which public

3 As Tim Harford (2007, Part 2, p. 3) pointed out in a recent "Dear Economist" column in the Financial Times, it might seem sensible for a company to judge its ice cream sales force on total sales, but having information about the weather allows for a better assessment of the contribution of the sales team to actual sales. 
policy must deal with this situation; the objectives are high quality education and teaching but there exists wide disagreement over how to define and measure these qualities.

Because social welfare does depend on inflation and inflation can be observed, one might use inflation as a type of performance measure, holding the central bank accountable for achieving a low and stable inflation rate. Inflation targeting can be thought of as defining a performance measure for the central bank. The critical issue in choosing any performance measure, however, is how powerful one wants to make the incentives. If accountability is based strictly on realized inflation and the consequences of missing the target are large, then the central bank will naturally focus on achieving the target, even if this means sacrificing other, more difficult to measure, aspects of social welfare. The concern that inflationtargeting produces too much of a focus on inflation control is at the heart of most criticisms of inflation targeting in the United States.

But this is where transparency becomes particularly important. Greater transparency can lessen the need to rely on a single easily measured performance indicator. When there is greater transparency, and the public is able to assess the same information the central bank has used to set policy, it is no longer necessary to base central bank accountability on inflation outcomes only (Walsh, 1999).

\section{Transparency and the Effectiveness of Monetary Policy}

Poole's second goal of transparency, promoting policy effectiveness, requires that private sector decisions be influenced, and influenced systematically, by the information central banks provide. With the development of New Keynesian models and their emphasis on the importance of forwardlooking behavior, managing expectations to improve policy effectiveness has taken on a new importance. Woodford (2005) has gone so far as to state that "not only do expectations about policy matter, but, at least under current conditions, very little else matters."4

4 Italics in the original.
The intuition for Woodford's statement is straightforward. Policymakers control directly only a short-term interest rate. Yet rational agents are forward looking and so base their spending and pricing decisions on their assessment of future interest rates, not just current rates. The recognition that expectations matter is not confined to academics; a recent article in the Financial Times (Guha, 2007) states that "What really matters, both for the markets and the economy, is not the current policy rate but the expected path of future rates."

Transparency and its relationship to policy effectiveness played a key role in the large literature that focused on the average inflation rate bias that could arise under optimal discretionary policy. By and large, this literature emphasized political and operational transparency, and it employed models in which policy surprises were the source of the real effects of monetary policy. Geraats (2002) provides an excellent survey of the literature.

In these models, the central bank preferences were generally treated as stochastic and unknown. The policy instrument was also taken to be observed with error or subject to a control error. For example, the central bank might control nonborrowed reserves, but this allowed only imperfect control of the money supply. ${ }^{5}$ Observing money growth would not provide enough information for the public to disentangle the effects of control errors from shifts in central bank preferences.

Thus, there was opaqueness about political objectives and operational implementation. Transparency was typically modeled as a reduction in the noise in the signal on the policy instrument. The optimal degree of transparency ensured the public would learn quickly when the central bank preferences shifted, but still left open the possibility that the bank could create a surprise if one was needed to aid stability. Cukierman and Meltzer (1986) showed that the central bank may prefer to adopt a less efficient operating procedure than

\footnotetext{
5 See, for example, Cukierman and Meltzer (1986) and Faust and Svensson (2002).
} 
is technically feasible (i.e., not reduce the control error variance to its minimum possible level). ${ }^{6}$

As emphasized in recent discussions of transparency, however, New Keynesian models imply that it is predictable monetary policies, not surprises, that are most effective in achieving policy goals. In such an environment, transparency, rather than reducing the efficacy of policy can actually increase it. Central bank announcements about future policy actions, or about future economic developments, can affect private sector expectations of future interest rates, inflation, and economic activity. With spending and pricing decisions dependent on these expectations, using announcements to influence expectations gives the central bank an additional policy instrument. As such, it serves to make policy more effective. The argument that transparency can increase the effectiveness of monetary policy is certainly more consistent with the modern practice of central banks, which has been uniformly to move in the direction of greater transparency.

But providing information to the public may have potential costs. These costs are associated with the conditional nature of any forecast. Some economists have worried that the public will not understand the distinction between a conditional and an unconditional forecast. ${ }^{7}$ Particularly because reputation is important, deviating from a previously announced policy path may be interpreted as a deviation from a commitment equilibrium rather than as an appropriate response based on new information. If a central bank fails to raise interest rates after signaling that it planned to, the private sector may believe the bank has become less concerned about inflation, causing inflation expectations to rise. Financial market participants may underestimate the conditionality of the announced rate path and so view deviations as introducing unwarranted uncertainty into financial markets. These factors may make the central

\footnotetext{
6 See also Faust and Svensson (2002), who show that, when the choice of transparency is made under commitment, patient central banks with small inflation biases will prefer minimum transparency. They argue that this result might account for the (then) relatively low degree of transparency that characterized the U.S. Federal Reserve System.

7 Goodhart (2006).
}

bank reluctant to adjust rates, producing a lock-in effect that would reduce flexibility and limit policy effectiveness.

Even when the public understands the conditional nature of the guidance provided by the central bank, announcements may introduce new sources of volatility. The influential paper by Morris and Shin (2002) has highlighted one channel through which central bank announcements may have a detrimental effect. Unlike standard models that assume all private agents share the same information, Morris and Shin focus on the more realistic case in which private agents have individual, heterogeneous sources of information and must attempt to forecast what others are expecting. ${ }^{8}$ Morris and Shin have argued that there can be a cost to providing more-accurate public information; agents may overreact to public information, making the economy more sensitive to any forecast errors in the public information.

Subsequent research (e.g., Hellwig, 2004, and Svensson, 2006) has suggested that the MorrisShin result is not a general one and that better, more accurate, central bank information is welfare improving. However, just as the earlier literature on transparency employed models at odds with current policy frameworks (only surprises mattered, the money supply was the instrument), the Morris-Shin analysis is conducted within a framework that fails to capture important aspects of actual monetary policy. For example, the issue facing most central banks is not whether to provide more-accurate forecasts. Instead, the issue is whether or not to provide more information by, for example, announcing forecasts. And even in the absence of explicit announcements or guidance, central banks already provide information through the setting of the policy instrument. The impact of a change in the policy instrument will depend, in part, on the information that it conveys about the central bank's view of the economy.

The work by Morris and Shin has been extended by Amato and Shin (2003), who cast the Morris-Shin analysis in a more standard macro model. In their model, the central bank has per-

8 Woodford (2003) has investigated the role of higher-order expectations in inducing persistent adjustments to monetary shocks in the Lucas-Phelps islands model. See also Hellwig (2002). 
fect information about the underlying shocks. This ignores the uncertainty policymakers themselves face in assessing the state of the economy. Nor do Amato and Shin allow the private sector to use observations on the policy instrument to draw inferences about central bank information. They also assume one-period price setting and represent monetary policy by a price level-targeting rule. In Hellwig (2004), prices are flexible and policy is given by an exogenous stochastic supply of money; private and public information consists of signals on the nominal quantity of money.

The potential costs and benefits of releasing central bank forecasts have also been analyzed by Geraats (2005). However, Geraats assumes agents do not observe the bank's policy instrument prior to forming expectations and employs a traditional Lucas supply function. Her focus is on reputational equilibria in a two-period model with a stochastic inflation target. Thus, the model and the issues addressed differ from the focus on the role of information in a Morris-Shin-like environment.

Rudebusch and Williams (2006) and Gosselin, Lotz, and Wyplosz (forthcoming) focus specifically on the provision of future interest rate projections. Rudebusch and Williams explore the role of interest rate projections in a model of political transparency - the asymmetry of information pertains to policy preferences and the central bank inflation target. Transparency is modeled as reducing noise in central bank projections. In contrast to the model I develop in the next section, Rudebusch and William incorporate learning and find that the public's ability to learn and welfare increase when interest rate projections are provided.

Gosselin, Lotz, and Wyplosz (forthcoming) adopt a quite different approach and focus on what they characterize as creative opacity. In their model, the private sector learns from the information released by the central bank, but the central bank also learns about private sector information by observing long-term interest rates. By providing its projection for the short-term interest rate, the central bank is able to recover private sector information from the long-term rate. This aligns expectations but may require the central bank to distort its current interest rate setting to achieve the desired long-term rate. If central bank information is poor, it may be better to remain opaque. Although the role of central bank learning is a critical one, I ignore it in the model in the next section in order to focus on the way inflation and output are affected by central bank announcements.

Thus, several questions remain unresolved concerning the role of transparency in an environment in which agents have heterogeneous information and central bank actions and announcements are commonly available. Specifically, how does the information conveyed by the central bank instrument affect the central bank's incentives and alter the effectiveness of policy? ${ }^{9}$ What is the effect of more information as opposed to better information? And are concerns about the added uncertainty of greater transparency warranted? These questions are addressed in the model in the next section.

\section{WELFARE EFFECTS OF OPAQUENESS AND TRANSPARENCY}

To investigate the role of economic transparency, I employ a simple model motivated by New Keynesian models based on Calvo-type pricing adjustment by monopolistic firms and by Morris and Shin's (2002) demonstration of the role heterogenous information can play. ${ }^{10}$ Like Gosselin, Lotz, and Wyplosz (forthcoming), I assume the central bank's preferences are known. Unlike their model, however, I incorporate the common-knowledge effect central to the Morris and Shin model. However, I focus on how the private sector learns from information provided by the central bank and ignore the reverse inference, where the central bank learns from private sector information, which is key in the Gosselin, Lotz, and Wyplosz model.

The basic model is similar to the one employed in Walsh $(2007 a, b)$. In these earlier papers, how-

\footnotetext{
9 In Walsh (2007b), I show that this incentive effect under discretion can make it socially optimal to appoint a Rogoff-conservative central banker, that is, a central banker who places less weight on outputgap stabilization than society does.

${ }^{10}$ As noted earlier, in the basic Morris-Shin model, Svensson (2006) shows that for almost all parameter values, better central bank information is welfare improving.
} 
ever, only demand and cost shocks were present, so it was necessary to make just a single projection (of inflation or the output gap) to fully reveal the central bank information (because the public also observed the policy instrument). The primary focus was also on partial transparency in the sense of Cornand and Heinmann (2004). The chief contributions of the present paper are to enrich the information structure, to account fully for the welfare costs of relative price dispersion created by heterogeneous information, and to assess transparency in terms of both quantity (the role of providing more information) and quality (the effect of better information).

Firms receive private signals on the fundamental shocks affecting the economy. Each period, a fraction of firms adjust their prices. In doing so, they are concerned with their relative price and so must attempt to forecast what other priceadjusting firms are doing. But this requires the individual firm to predict what other firms are predicting about the shocks hitting the economy. Hence, higher-order expectations will matter, as in Morris and Shin (2002).

The central bank, like individual firms, is assumed to possess potentially noisy information on the economic outlook. I consider two policy regimes. In the first, the opaque regime, denoted by superscript $o$, the central bank makes no announcements. However, even in this regime, the central bank reveals something about its outlook for the economy when it sets its policy instrument. In the absence of other information, the private sector forms expectations by combining the observation on the instrument with their own private information. A rise in the policy interest rate, for example, will be interpreted partially as a central bank attempt to offset a projected positive demand shock and partially as an attempt to contract real output to offset a positive cost shock. When deciding on its policy, the central bank needs to take into account how the public will interpret its actions because the instrument conveys information.

The second regime, denoted by superscript $f$, corresponds to full transparency. In this regime, the central bank releases its projections on future economic developments. Because it is on this information that the central bank bases its policy decision, the actual setting of the instrument conveys no additional information. The benefits of this regime are that private sector forecasts are improved and, because there is more common information across firms, relative price dispersion is reduced. The potential cost is that private expectations react to what may turn out ex post to be central bank forecast errors.

While I assume the central bank operates in a discretionary manner in setting its policy instrument, I also assume it can commit to a policy regime (opaque or transparent).

\section{The Basic Model}

The underlying model of price adjustment is based on Calvo, combined with the timing assumptions of Christiano, Eichenbaum, and Evans (2005) and the addition of firm-specific information. The Christiano, Eichenbaum, and Evans timing implies that firms who adjust their price for period $t$ do so based on $t-1$ information. Expressed alternatively, firms in period $t$ make decisions about their prices for period $t+1$. Because information differs across firms, price-setting firms will not all set the same price as in the standard common-information framework that is employed in most models. In addition, because firms care about their relative price, they must forecast the aggregate $t+1$ price level when they set their individual price for that period. This also differs from standard specifications in which firms are assumed to know the aggregate equilibrium price level when they set their price level.

Three types of shocks are considered: (i) costs shocks that are assumed to represent inefficient volatility in real marginal costs; (ii) aggregate demand shocks; and (iii) shocks to the gap between the economy's flexible-price equilibrium level of output and its efficient level of output. The last one will be referred to as a welfare-gap shock. The model differs from standard New Keynesian models in that the same information is not commonly available to all firms and firms must set prices before observing the current realizations of shocks.

The basic timing is as follows: 
(i) At the end of period $t$, the central bank forms projections about $t+1$ economic conditions and sets its policy instrument, $\theta_{t}$.

(ii) Firms observe $\pi_{t}, x_{t}$, and $\theta_{t}$ as well as individual specific signals about $t+1$ shocks. Firms may also observe announcements made by the central bank.

(iii) Those firms that can adjust their price set prices for $t+1$.

(iv) Period $t+1$ shocks occur and $\pi_{t+1}$ and $x_{t+1}$ are realized.

A randomly chosen fraction $1-\omega$ of firms optimally set their price for period $t+1$. If $\beta$ is the discount factor (see Walsh, 2007b), one can show that

$$
\begin{aligned}
& \pi_{j, t+1}^{*}=(1-\omega) E_{t}^{j} \bar{\pi}_{t+1}^{*}+(1-\omega \beta) \kappa E_{t}^{j} x_{t+1} \\
& +(1-\omega \beta) E_{t}^{j} e_{t+1}^{s}+\left(\frac{\omega \beta}{1-\omega}\right) E_{t}^{j} \pi_{t+2},
\end{aligned}
$$

where $\pi_{j, t+1}^{*}$ is the log price firm $j$ sets for period $t+1$ relative to the period $t$ average log price level (i.e., $p_{j, t+1}^{*}-p_{t}$ ); $E_{t}^{j} \bar{\pi}_{t+1}^{*}$ is firm $j$ 's expectation about the average $\pi_{i, t+1}^{*}$ being set by other adjusting firms; $E_{t}^{j} X_{t+1}$ is firm $j$ 's expectation about the output gap in $t+1 ; e_{t+1}^{s}$ is the aggregate, common cost shock; and $E_{t}^{j} \pi_{t+2}$ is firm $j$ 's expectation about future inflation. For simplicity, I assume (1) is linearized around a zero-inflation steady state.

To keep the model simple, I represent the demand side of the model in a very stylized, reduced-form manner. Monetary policy is represented by the central bank's choice of $\theta_{t}$ and by any announcements the central bank might make. I assume $\theta_{t}$ is observed at the start of the period so that any firm that sets its price in period $t$ can condition its choice on the central bank's policy action. The output gap is then equal to

$$
x_{t+1}=\theta_{t}+e_{t+1}^{v},
$$

where $e_{t+1}^{V}$ is a demand shock. Although I will call $\theta_{t}$ the central bank instrument, it essentially represents the central bank's intended output gap.

Information. As noted, there are three fundamental disturbances in the model: $e_{t}^{s}$ represents cost factors that, for a given output gap and expectations of future inflation, generate ineffi- cient inflation fluctuations; $e_{t}^{V}$ the aggregate demand disturbance; and $e_{t}^{u}$ a shock to the gap between the flexible-price output gap and the efficient output gap. I assume each is serially and mutually uncorrelated.

Firms must set their prices and the central bank must set its policy instrument before learning the actual realizations of the aggregate shocks. Firm $j$ 's idiosyncratic information, $e_{j, t+1}^{i}$ for $i=s$, $v, u$, is related to the aggregate shock according to

$$
e_{j, t+1}^{i}=e_{t+1}^{i}+\phi_{j, t+1}^{i}, \quad i=s, v, u .
$$

The $\phi_{j, t+1}^{i}$ terms are identically and independently distributed across firms and time. These signals are private in that they are unobserved by other agents. For convenience, each $\phi_{j, t+1}^{i}$ will be referred to as a noise term, even though $\phi_{j, t+1}^{s}$ is actually the idiosyncratic component of the firm's cost shock. All stochastic variables are assumed to be normally distributed. Define the signal-to-noise ratio, $\gamma_{j}^{i}=\sigma_{i}^{2} /\left(\sigma_{i}^{2}+\sigma_{j, i}^{2}\right)$, where $\sigma_{i}^{2}$ is the variance of $e^{i}$ and $\sigma_{j, i}^{2}$ is the variance of $\phi_{j}^{i}$. Let $\Omega_{j, t+1}$ denote the vector of private signals received by firm $j$, and let $\Omega_{t+1}=\int \Omega_{j, t+1}$ be the information aggregated across firms.

The central bank combines its information, models, and judgment to obtain forecasts of future economic disturbances. It will be convenient to represent this information, in parallel with the treatment of firm information, as signals on the three aggregate disturbances:

$$
e_{c b, t}^{i}=e_{t+1}^{i}+\phi_{c b, t}^{i}, \quad i=s, v, u .
$$

The noise terms $\phi_{c b}^{i}$ are assumed to be independently distributed and to be independent of $\phi_{j}^{i}$ for all $i, j$, and $t$. Define $\gamma_{c b}^{i}=\sigma_{i}^{2} /\left(\sigma_{i}^{2}+\sigma_{i, c b}^{2}\right)$, where $\sigma_{i, c b}^{2}$ is the variance of $\phi_{c b}^{i}$. Let $\Omega_{c b, t+1}$ denote the innovation to the central bank information set. Let $Z_{t}^{\prime}=\left[\begin{array}{lll}e_{t}^{s} & e_{t}^{v} & e_{t}^{u}\end{array}\right]$. Then $E_{t}^{c b} Z_{t+1}=\Gamma_{c b} \Omega_{c b, t+1}$, where $E^{c b}$ denotes expectations conditional on central bank information and

$$
\Gamma_{c b}=\left[\begin{array}{ccc}
\gamma_{c b}^{s} & 0 & 0 \\
0 & \gamma_{c b}^{V} & 0 \\
0 & 0 & \gamma_{c b}^{u}
\end{array}\right] .
$$

The central bank's objective is to minimize, under discretion, a standard quadratic loss func- 
tion that depends on inflation variability and output-gap variability. Specifically, loss is given by

$$
L_{t}^{c b}=E_{t}^{c b} \sum_{i=0}^{\infty} \beta^{i}\left[\pi_{t+i}^{2}+\lambda_{x}\left(x_{t+i}-e_{t+i}^{u}\right)\right],
$$

where $e_{t}^{u}$ is equal to stochastic variation in the gap between the flexible-price output gap $(x)$ and the welfare-maximizing output gap.

With staggered price adjustment, New Keynesian models imply that the welfare costs of inflation variability arise from the dispersion of relative prices it generates (Rotemberg and Woodford, 1997, Woodford, 2003a). Relative price dispersion can arise from inflation (because of staggered price adjustment) and because of heterogeneous information across firms. It can be shown (see the appendix) that the variance of relative prices across firms depends on $\pi_{t}^{2}$ and on the noise in the signals received by individual firms. Thus, social loss is given by

(4) $L_{t}^{s}=E_{t} \sum_{i=0}^{\infty} \beta^{i}\left[\pi_{t+i}^{2}+\lambda_{I} z_{t+i}^{2}+\lambda_{x}\left(x_{t+i}-e_{t+i}^{u}\right)\right]$,

where $z_{t}^{2}$ is relative price dispersion arising from heterogenous information across individual firms, with the appropriate weight on this source of loss relative to $\pi_{t}^{2}$ given by

$$
\lambda_{I}=\frac{(1-\omega)^{2}}{\omega} .
$$

The loss associated with heterogeneous information can be reduced if the central bank provides more information. However, this loss is not affected by the period-by-period policy choice the central bank makes in setting its instrument (conditional on the policy regime that defines the type of announcements the central bank makes). Thus, under discretion, the central bank takes as given the term $z_{t}^{2}$ in (4), which is due to heterogeneous information, and minimizes (3).

We can now evaluate equilibrium under each policy regime.

\section{Equilibrium Under the Opaque Regime}

In regime $o$, firms observe their own private signals and the central bank instrument. In regime $f$, the central bank provides its forecasts (equivalently, its signals) directly to the public. ${ }^{11}$ In the absence of central bank announcements, firm $j$ 's new information is given by its private signals and the policy instrument. The new information available to firm $j$ consists of $\Omega_{j, t+1}$ and $\theta_{t}$. Assume beliefs about monetary policy are

$$
\theta_{t}=\delta^{o} E_{t}^{c b} \psi_{t+1}=\delta^{o} \Gamma_{c b} \Omega_{c b, t+1},
$$

where $\delta^{0}$ is $1 \times 3$. These beliefs are consistent with a rational expectations equilibrium under discretionary monetary policy.

Define $\Theta^{o}=\left[\begin{array}{ll}\Theta_{1}^{o} & \Theta_{2}^{o}\end{array}\right]$ such that $\Theta_{1}^{o}$ is $3 \times 3$ and $\Theta_{2}^{o}$ is $3 \times 1$, where the $i j$ th element of $\Theta_{1}^{o}$ gives the effect of the firm's $j$ th signal on its forecast of the $i$ th shock. Similarly, the $i$ th element of $\Theta_{2}^{o}$ is the effect of $\theta_{t}$ on the firm's forecast of the $i$ th shock. Firm j's expectation of $Z_{t+1}$ is

$$
E_{t}^{j} Z_{t+1}=\Theta_{1}^{o} \Omega_{j, t+1}+\Theta_{2}^{o} \theta_{t} .
$$

Because the firm's signals on the different shocks are uncorrelated, $\Theta_{1}^{o}$ would, in the absence of the observation of $\theta_{t}$, consist of a diagonal matrix with signal-to-noise ratios along the diagonal. The offdiagonal elements of $\Theta_{1}^{o}$ can be nonzero when the firm combines its own information with $\theta_{t}$ to forecast the shocks. For example, suppose $\theta_{t}>0$. This might indicate a response by the central bank to a negative demand shock, a negative cost shock, or a positive welfare-gap shock. If the firm's signal on the demand shock is positive, then given $\theta_{t}$, this makes it less likely the central bank is reacting to a negative demand shock. The firm will therefore alter its forecast of cost and target shocks.

As shown in the appendix, the equilibrium strategy for firm $j$ will take the form

$$
\pi_{j, t+1}^{*}=b_{1}^{o} \Omega_{j, t+1}+b_{2}^{o} \theta_{t},
$$

where $b_{1}^{o}$ is $1 \times 3$. Under both regimes, the expression for the coefficients on $\Omega_{j, t+1}$ in the firm's equilibrium strategy takes the same form. ${ }^{12}$

\footnotetext{
${ }^{11}$ Alternatively, the central bank could announce its inflation and output-gap forecasts; combined with the observed instrument setting, these announcements would fully reveal the central bank's signals.

${ }^{12}$ Of course, their values differ under the two regimes to the extent that the information available to firms differs.
} 
The appendix shows also that the impact of the instrument on an individual firm's pricing decision is

(6)

$$
\begin{aligned}
& b_{2}^{o}=\left(\frac{1-\omega \beta}{\omega}\right) \kappa \\
& +\left(\frac{1}{\omega}\right)\left[(1-\omega) b_{1}^{o}+(1-\omega \beta)\left(l_{1}+\kappa l_{2}\right)\right] \Theta_{2}^{o},
\end{aligned}
$$

where $t_{i}$ is a $3 \times 1$ vector of zeros with a 1 in the $i$ th place. Equation (6) illustrates the channels through which a policy action affects the pricing decisions of firms. The first term, $(1-\omega \beta) \kappa / \omega$ is the standard effect operating through the output gap. Because inflation is $(1-\omega)$ times the pricing decision of the individual firm in a standard New Keynesian model, the effect on aggregate inflation operating through this terms would be $(1-\omega)$ $(1-\omega \beta) \kappa / \omega$, which is the normal coefficient on the output gap in a New Keynesian model based on Calvo pricing.

The remaining terms on the right side in (6) represent the informational effects of policy actions. For example, observing $\theta_{t}$ affects the firm's expectations about cost, given by the term $(1-\omega \beta) l_{i} \Theta_{2}^{o}$, and demand shocks, given by the term $(1-\omega \beta) \kappa l_{i} \Theta_{2}^{o}$. Observing $\theta_{t}$ also affects individual pricing decisions through the firm's expectations of what other firms are expecting, the $(1-\omega) b_{1}^{o}$ term.

Equilibrium inflation is given by

$$
\pi_{t+1}=(1-\omega) \bar{\pi}_{t+1}^{*}=(1-\omega)\left(b_{1}^{o} \Omega_{t+1}+b_{2}^{o} \theta_{t}\right)
$$

and

$$
\frac{\partial \pi_{t+1}}{\partial \theta_{t}}=(1-\omega) b_{2}^{o}
$$

The information channel can significantly affect the extent to which the central bank instrument impacts inflation. I calibrate the model by setting $\omega=0.65$ (as a compromise between micro evidence suggesting $\omega$ on the order of 0.5 and time-series estimates typically on the order of 0.8$)$, $\beta=0.99$, and $\kappa=1.8$. These values imply $(1-\omega)$ $(1-\omega \beta) \kappa / \omega=0.3455$. The standard deviations of all shocks are set equal to 1 . Figure 1 shows how $(1-\omega) b_{2}^{o}$ varies with the quality of private sector information, as measured by the signal-to-noise ratio, $\gamma_{j}^{i}$. When firms have perfect information on the shocks $\left(\gamma_{j}^{i}=1\right)$, the policy instrument, $\theta$, conveys no information and its effect on inflation equals 0.3455 , which is shown by the horizontal line in Figure 1.

However, when $\theta$ conveys information (i.e., when $\gamma_{j}^{i}<1$ ), its impact on inflation is significantly reduced. Movements in $\theta$ are partially attributed to the central bank's response to the various shocks. A rise in $\theta$, for example, lowers firms' forecasts of demand shocks. Because the net effect on the expected output gap is $\theta_{t}+E_{j}^{i} e_{t+1}^{v}$, the effect on price-setting behavior and inflation is less than the change in $\theta$. A rise in $\theta$ also leads firms to reduce their forecast of cost shocks, partially offsetting the positive impact of a rise in $\theta$ on inflation. For a given quality of private sector information, the information channel becomes more important as central bank information improves and private firms place more weight on the information conveyed by policy actions. The informational effects are larger, therefore, when the central bank has better quality information (in Figure 1, compare the solid line for $\gamma_{c b}^{i}=0.5$ with the dashed line for $\gamma_{c b}^{i}=0.9$ ).

Operating in a discretionary regime, the central bank sets policy optimally in each period based on its current forecasts about the future state of the economy. The first-order condition for minimizing the expected value of the central bank's loss function (3) subject to (2) and (7) is given in the appendix. This first-order condition can be solved for the optimal policy responses, and their values are also given in the appendix.

The solution to the model is obtained numerically by beginning with initial values for the policy coefficients, using these to obtain $\Theta^{\circ}, b_{1}^{o}$, and $b_{2}^{o}$, and then obtaining new values for the policy coefficients. This process continues until convergence. Once the equilibrium values of $b_{1}^{o}$ and $b_{2}^{o}$ and the policy coefficients are obtained, aggregate inflation is given by

$$
\pi_{t+1}=(1-\omega)\left[\begin{array}{l}
\left(b_{1}^{o}+b_{2}^{o} \delta^{o} \Gamma_{c b}\right) \psi_{t+1} \\
+b_{2}^{o} \delta^{o} \Gamma_{c b} \phi_{c b, t+1}
\end{array}\right],
$$




\section{Figure 1}

\section{Elasticity of Inflation with Respect to the Policy Instrument in the Opaque Regime as a Function of the Quality of Private Information}

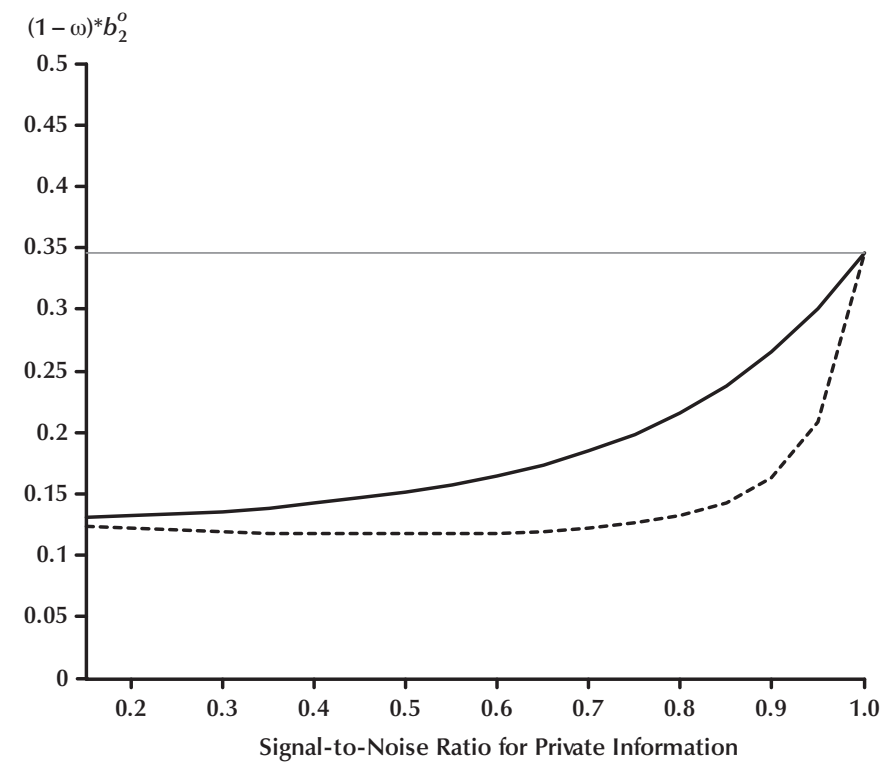

NOTE: Solid line, $\gamma_{c b}^{i}=0.5$; dotted line, $\gamma_{c b}^{i}=0.9$.

whereas the welfare gap is given by

$$
\begin{aligned}
& x_{t+1}-e_{t+1}^{u}=\theta_{t}+e_{t+1}^{v}-e_{t+1}^{u} \\
& =\delta^{o} \Gamma_{c b} \Omega_{c b, t+1}+\left(\imath_{2}-\imath_{3}\right) Z_{t+1} \\
& =\left(\delta^{o} \Gamma_{c b}+\imath_{2}-\imath_{3}\right) Z_{t+1}+\delta^{o} \Gamma_{c b} \phi_{c b, t+1} .
\end{aligned}
$$

\section{Equilibrium Under a Transparent Regime}

I interpret full transparency as a regime in which the central bank shares its information on the economy. Within the context of the model, this would mean that the central bank publishes its signals on the various disturbances so that $\Omega_{c b, t+1}$ becomes known to all firms. Equivalently, the central bank could publish its forecasts for inflation and the output gap. In a transparent regime, the instrument is no longer a source of information to the private sector. This alters the impact of $\theta_{t}$ on inflation and affects the central bank's incentives for setting policy. When the cen- tral bank provides its information to the public, the central bank information set is a subset of the public information set. In this context, Svensson and Woodford (2003) have shown that certainty equivalence holds and the policy decision of the central bank depends only on the expected values of the shocks. In particular, this implies that the optimal policy will be independent of the quality of either central bank information or private sector information.

$$
\text { Let } \Theta^{f}=\left[\Theta_{1}^{f} \Theta_{2}^{f}\right] \text { be the appropriate } 3 \times 6
$$
coefficient matrix such that

$$
E_{t}^{j} Z_{t+1}=\Theta_{1}^{f} \Omega_{j, t+1}+\Theta_{1}^{f} \Omega_{c b, t+1} .
$$

The appendix shows that the equilibrium strategy for price setting firms is

$$
\pi_{j, t+1}^{*}=b_{1}^{f} \Omega_{j, t+1}+b_{2}^{f} \theta_{t}+b_{3}^{f} \Omega_{c b, t+1},
$$

where $b_{1}^{f}$ takes the same form as $b_{1}^{o}$ (except when $\Theta_{1}^{f}$ replaces $\Theta_{1}^{o}$ in the expression for $b_{1}^{f}$ ). Although the formula $b_{1}^{f}$ is the same as for $b_{1}^{o}$, their values 
Table 1

Loss Under Alternative Regimes $\left(\sigma_{s}^{2}=\sigma_{v}^{2}=\sigma_{u}^{2}=1\right)$

\begin{tabular}{lccccc} 
& \multicolumn{3}{c}{$\gamma_{j}^{i}$} & $\mathbf{0 . 8}$ & \\
\cline { 2 - 6 } & $\mathbf{0 . 2}$ & $\mathbf{0 . 4}$ & $\mathbf{0 . 6}$ & & $\mathbf{1 . 0}$ \\
\hline$\gamma_{c b}^{i}=0.5$ & & & 11.70 & $\mathbf{1 3 . 5 2}$ & $\mathbf{1 6 . 7 9}$ \\
Opaque regime & $\mathbf{8 . 8 3}$ & $\mathbf{1 0 . 2 0}$ & $\mathbf{1 1 . 4 9}$ & $\mathbf{1 3 . 3 5}$ & $\mathbf{1 6 . 7 9}$ \\
Transparent regime & 9.52 & 10.33 & 1.80 & & 0 \\
$\pi$ Equivalent & 3.32 & 1.39 & & 7.66 & $\mathbf{7 . 6 4}$ \\
$\gamma_{c b}^{i}=0.9$ & & & 6.50 & $\mathbf{6 . 4 0}$ & $\mathbf{7 . 6 4}$ \\
$\quad$ Opaque regime & $\mathbf{4 . 5 6}$ & $\mathbf{5 . 5 5}$ & $\mathbf{6 . 2 2}$ & 3.60 & 0
\end{tabular}

NOTE: Bold indicates the regime with the least loss.

will differ as $\Theta^{f} \neq \Theta^{o}$. The effects of the central bank instrument and information are given by

$$
b_{2}^{f}=\frac{(1-\omega \beta)}{\omega} \kappa
$$

and

$$
b_{3}^{f}=\left(\frac{1}{\omega}\right)\left[(1-\omega) b_{1}^{f}+(1-\omega \beta)\left(l_{1}+\kappa l_{2}\right)\right] \Theta_{2}^{f} .
$$

Inflation will equal $(1-\omega) \bar{\pi}_{t+1}^{*}$, so

$$
\frac{\partial \pi_{t+1}}{\partial \theta_{t}}=(1-\omega) b_{2}^{f}=\frac{(1-\omega)(1-\omega \beta) \kappa}{\omega}
$$

and is independent of any informational effects. The exact expressions for the optimal policy response to each type of signal are given in the appendix.

\section{THE VALUE OF RELEASING INFORMATION}

We can now compare the effects of providing information by comparing outcomes under the opaque regime and the transparent regime. To assess outcomes under the two regimes, the model is solved using the same calibrated parameters as employed earlier (i.e., $\omega=0.65, \beta=0.99$, $\kappa=1.8$ ). I initially set the variances of all shocks equal to 1 . For the loss function, I set $\lambda_{x}=1 / 16$, reflecting the use of quarterly inflation rates.

Table 1 shows the loss under each regime for different combinations of the signal-to-noise ratios for both the private sector and the central bank. The first thing to note is the loss is increasing in the quality of private sector information (moving across rows from left to right) and decreasing in the quality of central bank information (comparing the top panel to the bottom panel). Better private information makes expectations more sensitive to signals and so increases the volatility of expectations. Greater volatility of expectations produces more inflation volatility. This is welfare decreasing. Better central bank information is welfare improving because it allows the central bank to engage in more effective stabilization policies that reduce the volatility of inflation and the output welfare gap. Although Morris and Shin (2002) suggest that improved commonly available information could reduce welfare, the results in Table 1 are consistent with Hellwig (2004) and Svensson (2006), who argue that better quality central bank information generally improves welfare.

When $\gamma_{j}^{i}=1$, firms observe the true shocks perfectly. In this case, the release of information or projections by the central bank is irrelevant and the loss is the same under both regimes, as shown in the last column of Table 1. When private 
Table 2

Components of Loss $\left(\sigma_{s}^{2}=\sigma_{v}^{2}=\sigma_{u}^{2}=1\right)$

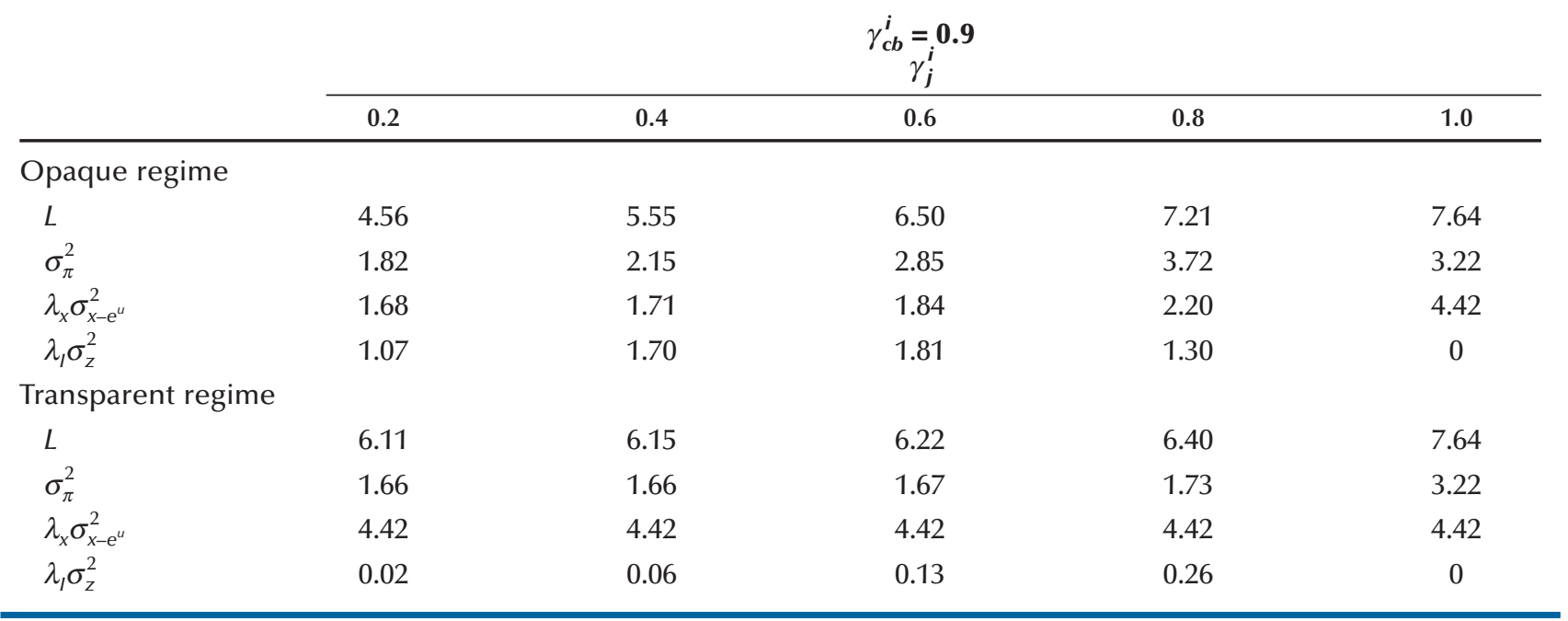

information is imperfect, loss differs under the two regimes (the regime with the least loss is indicated in bold). The rows labeled " $\pi$ equivalent" express the reduction in loss under the optimal regime in terms of the reduction in average inflation (expressed at annual rates) that would yield a similar reduction in loss. For example, if $\gamma_{j}^{i}=0.8$ and $\gamma_{c b}^{i}=0.5$, the improvement of moving from an opaque regime to a transparent one is equivalent to a reduction in inflation of 1.66 percentage points. The general results are similar in both the top panel, when central bank information is relatively poor (the signal and the noise have equal variances so that $\gamma_{c b}^{i}=0.5$ ), and the bottom panel, when central bank information is relatively good $\left(\gamma_{c b}^{i}=0.9\right)$. What matters is the quality of private information. If this is low, then the expectations of firms (and what individual firms expect that other firms are expecting) are sensitive to any commonly available information released by the central bank.

The results in Table 1 are robust to different values for the variances of the underlying shocks. ${ }^{13}$ The finding that transparency can lower welfare when private information is poor is suggestive of the Morris and Shin (2002) argument that noisy

\footnotetext{
${ }^{13}$ For each $\sigma_{i}^{2}$, the value was changed between 2 and 0.01 , whereas the other variances were held fixed at 1.
}

public information can decrease welfare. To investigate whether this is the effect that accounts for the relative performance of the two regimes, one can calculate the sources of loss under each regime. From (4), loss arises from inflation variability, welfare-gap variability, and relative price dispersion caused by heterogeneous information. Table 2 shows each of these components for the case $\gamma_{c b}^{i}=0.9$, which corresponds to the lower panel of Table 1 (results are similar for $\gamma_{c b}^{i}=0.5$ ).

Table 2 reveals three differences between the equilibria for the opaque and transparent regimes that are independent of the quality of private information. First, inflation is less volatile when policy is transparent. Second, the contribution of welfare-gap volatility to the overall loss is much larger when policy is transparent. And third, the welfare cost of relative price dispersion is much smaller when policy is transparent. When $\gamma_{j}^{i}$ is very low, opacity is the preferred regime because the welfare gap is much more stable. As will be discussed further below, the informational effects of policy actions are larger when the quality of private information is poor and thus these effects distort the incentive of the central bank such that policy reacts too little to cost shocks. This makes inflation more volatile but leaves the welfare gap more stable. Both inflation and output-gap volatil- 
Table 3

\begin{tabular}{|c|c|c|c|c|c|c|}
\hline \multicolumn{7}{|c|}{ Optimal Policy Coefficients $\left(\sigma_{s}^{2}=\sigma_{v}^{2}=\sigma_{u}^{2}=1\right)$} \\
\hline & \multicolumn{3}{|c|}{$\gamma_{j}^{i}=\mathbf{0 . 4}$} & \multicolumn{3}{|c|}{$\gamma_{j}^{i}=\mathbf{0 . 8}$} \\
\hline & $\delta^{s}$ & $\delta^{v}$ & $\delta^{u}$ & $\delta^{s}$ & $\delta^{v}$ & $\delta^{u}$ \\
\hline \multicolumn{7}{|l|}{$\gamma_{c b}^{i}=0.5$} \\
\hline Opaque regime & -0.0947 & -0.8884 & 0.7179 & -0.2510 & -0.9764 & 0.5246 \\
\hline Transparent regime & -0.3647 & -1.0000 & 0.3436 & -0.3647 & -1.0000 & 0.3436 \\
\hline \multicolumn{7}{|l|}{$\gamma_{c b}^{i}=0.9$} \\
\hline Opaque regime & -0.0816 & -0.8944 & 0.7475 & -0.1865 & -0.9713 & 0.6356 \\
\hline Transparent regime & -0.3647 & -1.0000 & 0.3436 & -0.3647 & -1.0000 & 0.3436 \\
\hline
\end{tabular}

ity in the opaque regime increase as $\gamma_{j}^{i}$ rises, so that the transparent regime becomes preferred when private sector information is good. ${ }^{14}$

Table 3 shows the optimal policy responses to three central bank signals for $\gamma_{j}^{i}$ equal to 0.4 and 0.8 and for $\gamma_{c b}^{i}$ equal to 0.5 and 0.9. Response coefficients in the transparent regime are independent of the quality of both private sector and the central bank information. This result follows from the demonstration by Svensson and Woodford (2003) that the central bank's decision problem satisfies the conditions for certainty equivalence if the private sector has more information than the central bank. This is the case in the transparent regime because the private sector knows both the central bank signals and their own private signals. The way informational effects in the opaque regime distort stabilization policy is clear from the muted response (in absolute value) to signals on the cost shock and amplified response to signals on the welfare-gap shock. The tradeoff between inflation and welfare-gap volatility is clearly present-policy under the transparent regime responds more to stabilize inflation and, as a result, the welfare gap is more volatile, as was shown in Table 2.

\footnotetext{
14 Also apparent in Table 2 is that, in the transparent regime, the volatility of the welfare gap is independent of the quality of private sector information. This reflects the certainty equivalence property that characterizes the policy choice of the central bank in the transparent regime. The central bank's setting of its instrument is independent of $\gamma_{j}^{i}$ and, as a result, so is the behavior of the output and welfare gaps.
}

In addition, transparency allows the central bank to more efficiently neutralize the effects of expected demand shocks. This can be seen by comparing the policy reaction coefficients under the two regimes. Under the transparent regime, expected demand shocks are completely offset (i.e., $\delta^{v}=-1$ ) regardless of the quality of private sector or central bank information. Under the opaque regime, $\delta^{v}=-1$ only when the public sector has perfect information on the shocks. Otherwise, $\delta^{v}$ is less than 1 in absolute value and demand shocks are not fully offset.

Under the opaque regime, when the policy instrument is moved, the public will confuse movements designed to offset forecasted demand shocks with movements designed to offset either cost or welfare-gap shocks. As a consequence, movements aimed at offsetting demand shocks can affect inflation expectations and cause actual inflation to fluctuate as the public attributes part of the instrument change to the other shocks. This makes it optimal to not offset demand shocks completely. Once the public can infer the central bank estimate of demand shocks, as it can under transparency, there is no longer any reason not to fully react to insulate the output gap and inflation from projected demand shocks, so $\delta_{2}^{V}=-1$.

In New Keynesian models, the welfare costs of inflation are the result of the relative price dispersion that arises with staggered price adjustment. Heterogeneous information among firms will also create relative price dispersion. Because information provided by the central bank is com- 


\section{Figure 2}

\section{Relative Price Dispersion Due to Heterogeneous Information}

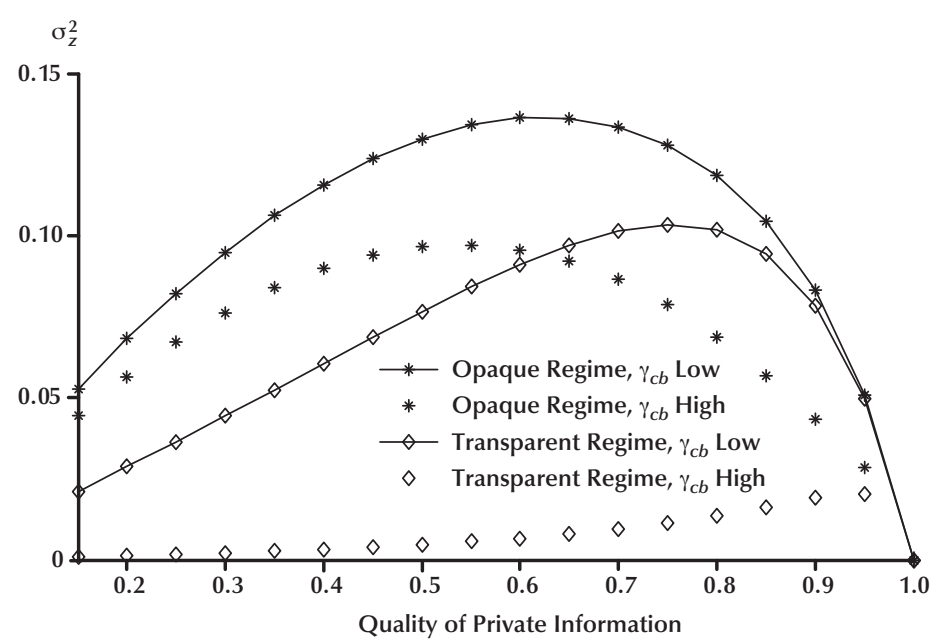

mon to all firms, it can help reduce relative price dispersion. Figure 2 shows the measure of relative prices dispersion that results from heterogeneous information among firms. The solid line with asterisks corresponds to the case of poor-quality central bank information $\left(\gamma_{c b}^{i}=0.5\right)$ under the opaque regime, and the unconnected asterisks correspond to the opaque regime with high-quality central bank information $\left(\gamma_{c b}=0.9\right)$. The diamonds indicate the outcomes under the transparent regime with poor-quality central bank information (the solid line) and high-quality central bank information (the unconnected diamonds).

When $\gamma_{j}^{i}=1$, all firms share the same information, so dispersion due to heterogeneous information goes to zero under either policy regime. When firms have very poor-quality information (i.e., for low initial values of $\gamma_{j}^{i}$ ) the heterogeneity of the information is high, but because the information is of poor quality, firms do not respond strongly to it. As information quality improves, firms react more strongly to their own private information and this increases price dispersion. Hence, relative price dispersion is initially increasing in $\gamma_{j}^{i}$.

Now consider the role of quality central bank information under the opaque regime. Relative price dispersion is lower when central bank infor- mation is good than when it is poor, though the loss from relative price dispersion actually constitutes a larger fraction of total social loss when central bank information is good. This is the result of the better stabilization the central bank can achieve when it has high-quality information on the economy. Not surprisingly, relative price dispersion is always lower under the transparent regime. For the same reason, high-quality central bank information reduces relative price dispersion under the transparent regime.

\section{CONCLUSIONS}

Under an opaque policy regime, where the private sector and the central bank do not share the same information, policy actions become a source of information to the public. And these policy actions have both direct effects on the output gap and indirect informational effects. Under an opaque regime, however, certainty equivalence does not hold and information channels affect the central bank's incentives. Optimal policy will depend on the quality of both central bank information and public information. In an opaque regime, the central bank stabilizes inflation less 
and the welfare gap more than it would in a transparent regime.

Under a completely transparent regime, the public sector has access to the central bank assessment of the economy. In this case, policy actions no longer provide any additional information. Optimal policy is independent of the quality of central bank information.

Consistent with the work of Svensson (2006) and Hellwig (2004), better central bank information was found to improve welfare. With better information, the central bank can implement more effective stabilization policies. The effect of providing more information by making announcements about projected inflation and the output gap is more ambiguous. Transparency always acts to lower relative price dispersion across firms by expanding the set of commonly available information, but central bank announcements can make expectations more volatile, particularly if firms have relatively poor information. Transparency dominates opacity when the private sector has relatively good information because in this case firms do not overreact to the information contained in central bank announcements. However, if private sector information is poor, central bank announcements can reduce welfare. So although better central bank information is desirable, more central bank information may not be.

\section{REFERENCES}

Amato, Jeffrey D. and Shin, Hyun Song. "Public and Private Information in Monetary Policy Models." Working Paper No. 138, Bureau of Labor Statistics, September 2003.

Andrews, Edmund L. "Bad News Puts Political Glare Onto Economy.” New York Times, September 8, 2007; http://www.nytimes.com/2007/09/08/business/ 08policy.html.

Atkins, Ralph; Mackenzie, Michael and Davies, Paul J. "ECB Chief Fails to Reassure Markets." Financial Times, August 15, 2007, p. 1.

Bernanke, Ben S. "The Recent Financial Turmoil and its Economic and Policy Consequences.” Presented at the Economic Club of New York, New York, NY, October 15, 2007.

Blinder, Alan S. "Monetary Policy Today: Sixteen Questions and About Twelve Answers." Presented at the Banco de España conference Central Banks in the 21st Century, June 2006.

Christiano, Lawrence J.; Eichenbaum, Martin and Evans, Charles. "Nominal Rigidities and the Dynamic Effects of a Shock to Monetary Policy." Journal of Political Economy, 2005, 113(1), 1-45.

Cornand, Camille and Heinemann, Frank. "Optimal Degree of Public Information Dissemination." Working Paper No. 1353, CESifo, December 2004.

Cukierman, Alex. "The Limits of Transparency." Presented at the session "Monetary Policy Transparency and Effectiveness" at the American Economic Association, January 2006.

Cukierman, Alex and Meltzer, Allan H. "A Theory of Ambiguity, Credibility, and Inflation under Discretion and Asymmetric Information." Econometrica, September 1986, 54(5): pp. 1099-128.

Dincer, Nergiz N. and Eichengreen, Barry. "Central Bank Transparency: Where, Why, and With What Effects?” NBER Working Paper No. 13003, National Bureau of Economic Research, March 2007.

Eijffinger, Sylvester C.W. and Geraats, Petra M. "How Transparent Are Central Banks?” European Journal of Political Economy, March 2006, 22(1), pp. 1-21.

Faust, Jon and Svensson, Lars E.O. "The Equilibrium Degree of Transparency and Control in Monetary Policy." Journal of Money, Credit, and Banking, May 2002, 34(2), pp. 520-39.

Geraats, Petra M. "Central Bank Transparency." Economic Journal, November 2002, 112(483), pp. 532-65.

Geraats, Petra M. “Transparency and Reputation: The Publication of Central Bank Forecasts" Topics in Macroeconomics, 2005, 5(1), pp 1-26. 
Goodhart, Charles A.E. "Letter to the Editor." Financial Times, June 29, 2006.

Gosselin, Pierre; Lotz, Aileen and Wyplosz, Charles. "The Expected Interest Rate Path: Alignment of Expectations vs. Creative Opacity Should Central Banks Reveal Expected Future Interest Rates?" International Journal of Central Banking (forthcoming).

Guha, Krishna. "Debate Unfolds on Likely Impact of Cut in US Interest Rates." Financial Times, September 6, 2007, p. 2.

Harford, Tim. "Dear Economist." Financial Times, September 1, 2007, Part 2, p. 3.

Hellwig, Christian. "Public Announcements, Adjustment Delays and the Business Cycle." UCLA, November 2002.

Hellwig, Christian. "Heterogeneous Information and the Benefits of Transparency." UCLA, December 2004.

Morris, Stephen and Shin, Hyun Song. "Social Value of Public Information." American Economic Review, December 2002, 92(5), pp. 1521-34.

Poole, William. "Communicating the Fed's Policy Stance." Presented at the HM Treasury/GES conference Is There a New Consensus in Macroeconomics? London, November 30, 2005; www.stlouisfed.org/ news/speeches/2005/11 30 05.htm.

Poole, William. "Fed Communications." Presented to the St. Louis Forum, February 24, 2006; www.stlouisfed.org/news/speeches/2006/ 0224 06.htm.

Rotemberg, Julio J. and Woodford, Michael. "An Optimizing-Based Econometric Model for the Evaluation of Monetary Policy," in Ben S. Bernanke and Julio J. Rotemberg, eds., NBER Macroeconomic Annual 1997. Cambridge, MA: MIT Press, 1997, pp. 297-346.
Rudebusch, Glenn D. and Williams, John C. "Revealing the Secrets of the Temple: The Value of Publishing Central Bank Interest Rate Projections." October 2006; also in J.Y. Campbell, ed., Asset Prices and Monetary Policy. Chicago: University of Chicago Press (forthcoming).

Svensson, Lars E.O. "Social Value of Public Information: Morris and Shin (2002) Is Actually Pro Transparency, Not Con." American Economic Review, March 2006, 96(1), pp. 448-51.

Svensson, Lars E. O. and Woodford, Michael. "Optimal Policy With Partial Information in a Forward-Looking Model: Certainty-Equivalence Redux.” NBER Working Paper No. w9430. National Bureau of Economic Research, January 2003.

Walsh, Carl E. "Announcements, Inflation Targeting and Central Bank Incentives." Economica, May 1999, 66(262), pp. 255-69.

Walsh, Carl E. "Transparency, Flexibility, and Inflation Targeting," in Frederic Mishkin and Klaus Schmidt-Hebbel, eds., Monetary Policy Under Inflation Targeting. Santiago, Chile: Banco Central de Chile, 2007a.

Walsh, Carl E. "Optimal Economic Transparency." International Journal of Central Banking." March 2007b, 3(1), pp. 5-30.

Woodford, Michael. Money, Interest, and Prices, Princeton: Princeton University Press, 2003.

Woodford, Michael. "Central Bank Communications and Policy Effectiveness." Presented at the Federal Reserve Bank of Kansas City symposium The Greenspan Era: Lessons for the Future, Jackson Hole, WY, August 2005.

Yellen, Janet L. "Policymaking on the FOMC: Transparency and Continuity." Federal Reserve Bank of San Francisco Economic Letter, No. 2005-22, September 2, 2005. 


\section{APPENDIX}

\section{Welfare Weight on Information Dispersion}

The welfare loss in New Keynesian models arises from inefficient price dispersion across firms. Let $p_{j, t}$ denote firm $j$ 's price and let $\bar{P}_{t}$ be the aggregate price level. Then

$$
\begin{aligned}
\Delta_{t} & \equiv \operatorname{var}_{j}\left(\log p_{j, t}-\bar{P}_{t-1}\right) \\
& =E_{t}\left(\log p_{j, t}-\bar{P}_{t-1}\right)^{2}-\left(E_{t} \log p_{j, t}-\bar{P}_{t-1}\right)^{2} \\
& =E_{t}\left(\log p_{j, t}-\bar{P}_{t-1}\right)^{2}-\left(\bar{P}_{t}-\bar{P}_{t-1}\right)^{2} .
\end{aligned}
$$

Using the assumptions of the Calvo model, the first term on the right can be written as

$$
E_{t}\left(\log p_{j, t-1}-\bar{P}_{t-1}\right)^{2}+(1-\omega) E_{t}\left(\log p_{j, t}^{*}-\log \bar{P}_{t-1}\right)^{2}=\omega \Delta_{t-1}+(1-\omega) E_{t}\left(\log p_{j, t}^{*}-\bar{P}_{t-1}\right)^{2}
$$

Now

$$
\log p_{j, t}^{*}-\bar{P}_{t-1}=\log p_{j, t}^{*}-\log \bar{p}_{t}^{*}+\log \bar{p}_{t}^{*}-\bar{P}_{t-1},
$$

where the first term on the right is zero in the standard New Keynesian model with common information across firms. Hence,

$$
E_{t}\left(\log p_{j, t}^{*}-\bar{P}_{t-1}\right)^{2}=E_{t}\left(\log p_{j, t}^{*}-\log \bar{p}_{t}^{*}\right)^{2}+\left(\log \bar{p}_{t}^{*}-\bar{P}_{t-1}\right)^{2}
$$

because the idiosyncratic noise is independent of the fundamental shocks. From the definition of inflation,

$$
\pi_{t}=(1-\omega)\left(\log \bar{p}_{t}^{*}-\bar{P}_{t-1}\right)
$$

so

$$
E_{t}\left(\log p_{j, t}^{*}-\bar{P}_{t-1}\right)^{2}=E_{t}\left(\log p_{j, t}^{*}-\log \bar{p}_{t}^{*}\right)^{2}+\left(\frac{1}{1-\omega}\right)^{2} \pi_{t}^{2}
$$

Combining these results,

$$
\begin{aligned}
\Delta_{t} & =\omega \Delta_{t-1}+(1-\omega) E_{t}\left(\log p_{j, t}^{*}-\log \bar{p}_{t}^{*}\right)^{2}+\left(\frac{1}{1-\omega}\right) \pi_{t}^{2}-\pi_{t}^{2} \\
& =\omega \Delta_{t-1}+(1-\omega) E_{t}\left(\log p_{j, t}^{*}-\log \bar{p}_{t}^{*}\right)^{2}+\left(\frac{\omega}{1-\omega}\right) \pi_{t}^{2} .
\end{aligned}
$$

It follows that

where

$$
E_{t} \sum_{i=0}^{\infty} \beta^{i} \Delta_{t+i}=\left(\frac{\omega}{1-\omega}\right)\left(\frac{1}{1-\omega \beta}\right) E_{t} \sum_{i=0}^{\infty} \beta^{i}\left[\pi_{t+i}^{2}+\lambda_{I}\left(\log p_{j, t+i}^{*}-\log \bar{p}_{t+i}^{*}\right)^{2}\right],
$$

$$
\lambda_{I}=(1-\omega)^{2} / \omega
$$




\section{The Opaque Regime}

Let

$$
\begin{gathered}
\sum=\left[\begin{array}{ccc}
\sigma_{s}^{2} & 0 & 0 \\
0 & \sigma_{V}^{2} & 0 \\
0 & 0 & \sigma_{u}^{2}
\end{array}\right], \\
\Sigma_{j}=\left[\begin{array}{ccc}
\sigma_{s}^{2}+\sigma_{j, s}^{2} & 0 & 0 \\
0 & \sigma_{V}^{2}+\sigma_{j, V}^{2} & 0 \\
0 & 0 & \sigma_{u}^{2}+\sigma_{j, u}^{2}
\end{array}\right],
\end{gathered}
$$

and

$$
\Sigma_{c b}=\left[\begin{array}{ccc}
\sigma_{s}^{2}+\sigma_{c b, s}^{2} & 0 & 0 \\
0 & \sigma_{V}^{2}+\sigma_{c b, V}^{2} & 0 \\
0 & 0 & \sigma_{u}^{2}+\sigma_{c b, u}^{2}
\end{array}\right] .
$$

In the absence of central bank announcements, firm j's new information is given by

$$
\left[\begin{array}{c}
e_{t+1}^{s}+\phi_{j, t+1}^{s} \\
e_{t+1}^{V}+\phi_{j, t+1}^{V} \\
e_{t+1}^{u}+\phi_{j, t+1}^{u} \\
\theta_{t}
\end{array}\right]=\left[\begin{array}{c}
\Omega_{j, t+1} \\
\theta_{t}
\end{array}\right],
$$

where

$$
\theta_{t}=\delta^{o} \Gamma_{c b} \Omega_{c b, t+1}
$$

Define

$$
\Theta^{o}=\left[\begin{array}{ll}
\Sigma & \Sigma \Gamma_{c b}^{\prime} \delta^{o^{\prime}}
\end{array}\right]\left[\begin{array}{cc}
\Sigma_{j} & \Sigma \Gamma_{c b}^{\prime} \delta^{o^{\prime}} \\
\delta^{o} \Gamma_{c b} \Sigma & \delta^{o} \Gamma_{c b} \Sigma_{c b} \Gamma_{c b}^{\prime} \delta^{o^{\prime}}
\end{array}\right]^{-1}=\left[\begin{array}{ll}
\Theta_{1}^{o} & \Theta_{2}^{o}
\end{array}\right],
$$

where $\Theta_{1}^{o}$ is $3 \times 3$ and $\Theta_{2}^{o}$ is $3 \times 1$. Thus, firm $j$ 's expectation of $Z_{t+1}$ is

$$
\begin{aligned}
E_{t}^{j} Z_{t+1} & =\Theta_{1}^{o} \Omega_{j, t+1}+\Theta_{2}^{o} \theta_{t} \\
& =\Theta_{1}^{o} \Omega_{j, t+1}+\Theta_{2}^{o} \delta^{o} \Gamma_{c b} \Omega_{c b, t+1} .
\end{aligned}
$$

The aggregate information (i.e., aggregated across all firms) is

$$
\left[\begin{array}{c}
\Omega_{t+1} \\
\theta_{t}
\end{array}\right]=\left[\begin{array}{c}
e_{t+1}^{s} \\
e_{t+1}^{V} \\
e_{t+1}^{u} \\
\theta_{t}^{u}
\end{array}\right]=\left[\begin{array}{c}
Z_{t+1} \\
\theta_{t}
\end{array}\right]
$$


Defining $l_{i}$ as a $1 \times 3$ vector with a 1 in the $i$ th place and zeros elsewhere, we can write (1), a firm's price adjustment, as

$$
\begin{aligned}
\pi_{j, t+1}^{*} & =(1-\omega) E_{t}^{j} \bar{\pi}_{t+1}^{*}+(1-\omega \beta) \kappa \theta_{t}+(1-\omega \beta)\left(u_{1}+\kappa l_{2}\right) E_{t}^{j} Z_{t+1}+\left(\frac{\omega \beta}{1-\omega}\right) E_{t}^{j} \pi_{t+2} \\
& =(1-\omega) E_{t}^{j} \bar{\pi}_{t+1}^{*}+(1-\omega \beta) \kappa \theta_{t} \\
& +(1-\omega \beta)\left(u_{1}+\kappa l_{2}\right)\left(\Theta_{1}^{o} \Omega_{j, t+1}+\Theta_{2}^{o} \theta_{t}\right)+\left(\frac{\omega \beta}{1-\omega}\right) E_{t}^{j} \pi_{t+2} .
\end{aligned}
$$

An equilibrium strategy for firm $j$ will take the form

$$
\pi_{j, t+1}^{*}=b_{1}^{o} \Omega_{j, t+1}+b_{2}^{o} \theta_{t},
$$

where $b_{1}^{o}$ is $1 \times 3$.

In forming expectations about the pricing behavior of other firms adjusting in the current period, firm $j$ 's expectation of $\bar{\pi}_{t+1}^{*}$ is given by

$$
\begin{aligned}
E_{t}^{j} \bar{\pi}_{t+1}^{*} & =b_{1}^{o} E_{t+1}^{j} \Omega_{t+1}+b_{2}^{o} \theta_{t} \\
& =b_{1}^{o} E_{t+1}^{j} Z_{t+1}+b_{2}^{o} \theta_{t} \\
& =b_{1}^{o}\left[\Theta_{1}^{o} \Omega_{j, t+1}+\Theta_{2}^{o} \theta_{t}\right]+b_{2}^{o} \theta_{t} \\
& =b_{1}^{o} \Theta_{1}^{o} \Omega_{j, t+1}+\left(b_{1}^{o} \Theta_{2}^{o}+b_{2}^{o}\right) \theta_{t} .
\end{aligned}
$$

Because

$$
\pi_{t+1}=(1-\omega) \bar{\pi}_{t+1}^{*}
$$

it follows that

$$
\begin{aligned}
E_{t}^{j} \pi_{t+2} & =(1-\omega) E_{t}^{j} \bar{\pi}_{t+2}^{*} \\
& =(1-\omega) E_{t}^{j}\left[b_{1}^{o} \Theta_{1}^{o} \Omega_{j, t+2}+\left(b_{1}^{o} \Theta_{2}^{o}+b_{2}^{o}\right) \theta_{t+1}\right] \\
& =0 .
\end{aligned}
$$

Substituting these into the equation for $\pi_{j, t+1}^{*}$ and collecting terms,

$$
\begin{aligned}
\pi_{j, t+1}^{*} & =(1-\omega) b_{1}^{o} \Theta_{1}^{o} \Omega_{j, t+1}+(1-\omega \beta)\left(l_{1}+\kappa l_{2}\right) \Theta_{1}^{o} \Omega_{j, t+1} \\
& +(1-\omega \beta) \kappa \theta_{t}+(1-\omega)\left(b_{1}^{o} \Theta_{2}^{o}+b_{2}^{o}\right) \theta_{t} \\
& +(1-\omega \beta)\left(l_{1}+\kappa l_{2}\right) \Theta_{2}^{o} \theta_{t} .
\end{aligned}
$$

Equating coefficients with the proposed solution yields

$$
b_{1}^{o}=\left[(1-\omega \beta)\left(l_{1}+\kappa l_{2}\right)\right] \Theta_{1}^{o}\left[I_{3}-(1-w) \Theta_{1}^{o}\right]^{-1} .
$$

The expression for $b_{2}^{o}$ is reported in the text.

The objective function under discretion involves minimizing

$$
E_{t}^{c b}\left[\pi_{t+1}^{2}+\lambda_{x}\left(x_{t+1}-e_{t+1}^{u}\right)^{2}\right]
$$


subject to (2) and (7). The first-order condition for the central bank decision problem under discretion is

$$
(1-\omega) b_{\theta} E_{t}^{c b} \pi_{t+1}+\lambda_{x}\left(\theta_{t}+E_{t}^{c b} e_{t+1}^{v}-E_{t}^{c b} e_{t+1}^{u}\right)=0 .
$$

From (7),

$$
\begin{aligned}
E_{t}^{c b} \pi_{t+1} & =(1-\omega) b_{1}^{o} E_{t}^{c b} \Omega_{j, t+1}+(1-\omega) b_{2}^{o} \theta_{t} \\
& =(1-\omega) b_{1}^{o} \Gamma_{c b} \Omega_{c b, t+1}+(1-\omega) b_{2}^{o} \theta_{t}
\end{aligned}
$$

because

$$
E_{t}^{c b} \Omega_{j, t+1}=E_{t}^{c b} Z_{t+1}=\Gamma_{c b} \Omega_{c b, t+1} .
$$

Hence, the first-order condition becomes

$$
\begin{aligned}
{\left[\lambda_{x}+(1-\omega)^{2}\left(b_{2}^{o}\right)^{2}\right] \theta_{t} } & =(1-\omega) b_{2}^{o} E_{t}^{c b} e_{t+1}^{u} \\
& -(1-\omega)^{2} b_{2}^{o} b_{1}^{o} \Gamma_{c b} \Omega_{c b, t+1}-\lambda_{x} E_{t}^{c b} e_{t+1}^{V} .
\end{aligned}
$$

This in turn implies that

$$
\begin{aligned}
{\left[\lambda_{x}+(1-\omega)^{2}\left(b_{2}^{o}\right)^{2}\right] \theta_{t} } & =-(1-w)^{2} b_{2}^{o} b_{1}^{o} \Gamma_{c b} \Omega_{c b, t+1} \\
& +\left[\begin{array}{lll}
0 & -\lambda_{x} & (1-\omega) b_{2}^{o}
\end{array}\right] \Gamma_{c b} \Omega_{c b, t+1}
\end{aligned}
$$

Hence,

$$
\theta_{t}=\delta^{o} \Gamma_{c b} \Omega_{c b, t+1},
$$

where $\delta^{o}=\left[\begin{array}{lll}\delta^{S} & \delta^{V} & \delta^{u}\end{array}\right]$ and

$$
\begin{gathered}
\delta^{s}=-\left[\frac{(1-\omega)^{2} b_{2}^{o} b_{11}^{o}}{\lambda_{x}+(1-\omega)^{2}\left(b_{2}^{o}\right)^{2}}\right] \\
\delta^{V}=-\left[\frac{\lambda_{x}+(1-\omega)^{2} b_{2}^{o} b_{12}^{o}}{\lambda_{x}+(1-\omega)^{2}\left(b_{2}^{o}\right)^{2}}\right] \\
\delta^{u}=\left[\frac{\lambda_{x}-(1-\omega)^{2} b_{2}^{o} b_{13}^{o}}{\lambda_{x}+(1-\omega)^{2}\left(b_{2}^{o}\right)^{2}}\right] .
\end{gathered}
$$

\section{The Transparent Regime}

In regime $f$, the central bank announces its signals so that firms observe $\Omega_{c b, t+1}$ directly. Firms' expectations now depend on $\Omega_{c b, t+1}$ and not directly on $\theta_{t}$. 
Guess an equilibrium strategy of the form

$$
\pi_{j, t+1}^{*}=b_{1}^{f} \Omega_{j, t+1}+b_{2}^{f} \Omega_{c b, t+1}+b_{3}^{f} \theta_{t} .
$$

Then, following the same procedures as used to solve the model without announcements, one finds that

$$
\begin{gathered}
b_{1}^{f}=\left[(1-\omega \beta)\left(l_{1}+\kappa l_{2}\right)\right] \Theta_{1}^{f}\left[I_{3}-(1-\omega) \Theta_{1}^{f}\right]^{-1} \\
b_{2}^{f}=\left(\frac{1}{\omega}\right)\left[(1-\omega) b^{f}+(1-\omega \beta)\left(l_{1}+\kappa l_{2}\right)\right] \Theta_{2}^{f} . \\
b_{3}^{f}=\frac{(1-\omega \beta)}{\omega} \kappa .
\end{gathered}
$$

Optimal policy in this regime satisfies the first-order condition

$$
(1-\omega) b_{3}^{f} E_{t}^{c b} \pi_{t+1}+\lambda_{x}\left(\theta_{t}+E_{t}^{c b} e_{t+1}^{v}-E_{t}^{c b} e_{t+1}^{u}\right)=0 .
$$

Note that

$$
E_{t}^{c b} \pi_{t+1}=(1-\omega)\left[\left(b_{1}^{f} \Gamma_{c b}+b_{2}^{f}\right) \Omega_{c b, t+1}+b_{3}^{f} \theta_{t}\right]
$$

because

$$
E_{t}^{c b} \Omega_{j, t+1}=\Gamma_{c b} \Omega_{c b, t+1} .
$$

Solving the first-order condition yields

$$
\theta_{t}=d^{f} \Gamma_{c b} \Omega_{c b, t+1},
$$

with $d^{f}=\left[\begin{array}{lll}d^{S} & d^{V} & d^{u}\end{array}\right]$ and

$$
\begin{aligned}
& d^{s}=-(1-\omega)^{2} b_{3}^{f}\left[\frac{\left(b_{21}^{f} / \gamma_{c b}^{s}\right)+b_{11}^{f}}{\lambda_{x}+\left(h^{f}\right)^{2}(1-w)^{2}}\right] \\
& d^{V}=-\left[\frac{\lambda_{x}+(1-\omega)^{2} b_{3}^{f}\left[\left(b_{22}^{f} / \gamma_{c b}^{v}\right)+b_{12}^{f}\right]}{\lambda_{x}+\left(b_{3}^{f}\right)^{2}(1-\omega)^{2}}\right] \\
& d^{u}=\left[\frac{\lambda_{x}-(1-\omega)^{2} b_{3}^{f}\left[\left(b_{23}^{f} / \gamma_{c b}^{u}\right)+b_{13}^{f}\right]}{\lambda_{x}+\left(b_{3}^{f}\right)^{2}(1-\omega)^{2}}\right] .
\end{aligned}
$$

